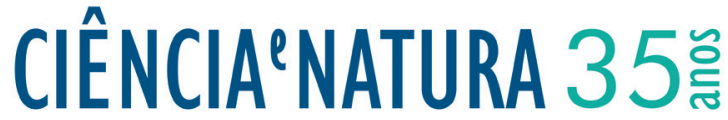

\section{Avaliação de monitorias realizadas em um centro de ciências}

\author{
The evaluation monitoring in a science center
}

\author{
Marco Aurélio Alvarenga Monteiro일 Isabel Cristina de Castro Monteiro², \\ Luciene de Fátima da Silva ${ }^{3}$, Alberto Gaspar ${ }^{4}$ \\ ${ }^{1,2,4}$ Doutor , Universidade Estadual Paulista Julio de Mesquita Filho, Bauru, Brasil \\ ${ }^{3}$ Mestre,Universidade Estadual Paulista Julio de Mesquita Filho, Bauru, Brasil
}

\begin{abstract}
Resumo
Neste trabalho buscamos investigar a interação social estabelecida entre monitores e alunos-visitantes de um museu de ciências, do ponto de vista de conhecimentos mobilizados por aquele na explicação do gerador de Van der Graaff. Nossa pesquisa se estabeleceu numa universidade pública que mantém um Centro de Ciências e registramos, em áudio e vídeo, os diálogos estabelecidos em torno de um experimento de demonstração. A análise dos dados se estabelece em torno da correção conceitual das explicações realizadas pelos monitores. Realizamos, também, uma entrevista estruturada a partir de uma única questão: qual a principal dificuldade enfrentada para planejar e conduzir sua apresentação no Centro de Ciências? Os resultados evidenciam que os monitores, em suas falas, não ultrapassam o processo de descrição do funcionamento do equipamento experimental, não sendo capazes, portanto, de estabelecer uma interação que propicie discussões de conceitos científicos com os visitantes. Nossa pesquisa também identificou que, apesar de a Universidade manter um Centro de Ciências, não há um vínculo entre a formação do professor e as atividades realizadas em espaços não-formais.
\end{abstract}

Palavras-chave: Ensino de Física. Alfabetização científica. Atividades de demonstração experimental.

\begin{abstract}
In this paper we investigate the social interaction established between monitors and student-visitors to a science museum in terms of knowledge mobilized by the explanation about principle operating of Van De Graff Generator. Our research was conducted at a university public that maintains a Center of Sciences and the data were collected through recording video and audio of the dialogues established around a demonstration experiment. Data analysis is established around the conceptual correctness of the explanations made by the monitors. We also conducted a structured interview from a single question: what is the main difficulty faced in planning and conducting his presentation at the Science Center? The results show that the monitors were not able to exceed the process description of the operation of the experimental equipment, not being able to establish an interaction that fosters discussions of scientific concepts with visitors. Our research also found that, although the university maintained a Sciences Center, not there is a link between teacher training and activities in non-formal settings.
\end{abstract}

Keywords: Physics teaching. Scientific literacy. Experimental demonstration activity. 


\section{Introdução}

Segundo dados apresentados no Anuário Brasileiro da Educação Básica (BRASIL, 2012a), somente 10 \% dos estudantes brasileiros que concluem o Ensino Médio demonstram dominar os conteúdos previstos para esse nível de Ensino. Essa realidade não é diferente quando o nível de ensino avaliado é o fundamental. Mesmo com melhoras no desempenho na Prova do PISA (Programme for International Student Assessment), avaliação internacional realizada pela OCDE (Organização para o Desenvolvimento e Cooperação Econômica), o Brasil ocupa a posição $57^{\circ}$ num ranking que conta com 67 países (BRASIL, 2012b). Esses resultados pouco animadores quanto à aprendizagem em Ciências em nossas escolas de Ensino Fundamental e Médio tem gerado preocupação, não só pelo fato de os estudantes apresentarem, nessa área do conhecimento, baixo desempenho nas escolas, mas também pela dificuldade deles perceberem a real importância dos conteúdos científicos em suas vidas.

Gruzman e Siqueira (2007) discutem o papel dos museus e centros de ciências, destacando que tais instituições, face às constantes transformações da sociedade, têm a missão de sensibilizar seus visitantes sobre o patrimônio cultural a partir de um diálogo constante. Desse modo, apontam para a própria transformação do significado de museus de ciências ao longo do tempo, evoluindo de uma concepção voltada a uma instituição encarregada do acondicionamento de equipamentos experimentais de demonstração para outra capaz de promover uma melhor compreensão pública da Ciência, da Tecnologia e de seus impactos no cotidiano das pessoas.

Pedretti (2006, apud Gruzman e Siqueira, 2007) considera que as ações nessas instituições devem oferecer muito mais do que simplesmente contribuir com a aprendizagem de conceitos científicos: devem possibilitar uma reflexão mais significativa quanto às questões sócio científicas.

Por esse prisma, os museus de ciências não podem se furtar a discutir o contrassenso de vivermos em uma sociedade dominada pela intensa produção de conhecimento e, ao mesmo tempo, convivermos com imensas incertezas, como a questão dos alimentos transgênicos, a clonagem, o uso da energia nuclear, entre outras.

Para isso, devem desenvolver estratégias didático -pedagógicas, conceber e incorporar reflexões sobre a natureza da aprendizagem e dos processos de comunicação e educação de forma a poder instigar a curiosidade, facilitar a compreensão de conceitos e informações, além de promover uma maior consciência individual e coletiva sobre o papel da ciência e da tecnologia sobre a sociedade e o meio ambiente.

Muitos desses desafios, que os autores afirmam que devem ser enfrentados pelas instituições de Educação não-formal, também são apontados como objetivos a serem alcançados pela escola.

Nesse sentido, trabalhos de pesquisa, como os de
Marandino (2001) e Valente et. al (2005), têm apontado para a necessidade de uma maior interação entre o ensino formal realizado no âmbito escolar e a educação científica realizada nos museus e centros de ciências.

Para Marandino (opus cit.), apesar de a escola e os museus de ciências serem espaços sociais que possuem histórias, linguagens e propostas educativas e pedagógicas diferentes, são instituições que se interpenetram e se complementam mutuamente de tal forma a se constituírem, juntas, em uma poderosa ferramenta no processo de formação do cidadão alfabetizado cientificamente.

Na mesma direção, Valente et. al. (opus cit.) afirmam que a Ciência e a Tecnologia estão presentes em diferentes contextos sociais, sejam eles pessoais (saúde, uso de medicamentos, entre outros) ou públicos (alimentos geneticamente modificados, camada de ozônio, energia nuclear etc.). Portanto, nessa perspectiva, concluem sobre a importância de se examinar como as modalidades ensino formal e não-formal podem contribuir, juntas, para auxiliarem as pessoas a entenderem os avanços científicos e tecnológicos que, atualmente, parametrizam suas vidas.

Assim, parece-nos fundamental discutir as possíveis interações a serem estabelecidas entre as escolas e os museus de ciências para que ações conjuntas possam ser planejadas e, de fato, realizadas.

Nessa perspectiva, uma possibilidade de elo pode ser estabelecida através do professor. Marandino (2003) chama atenção para a importância de se pensar a formação do professor para além da sala de aula, propiciando meios para a atuação em ações voltadas à divulgação do conhecimento científico em museus e centros de ciências.

$\mathrm{O}$ documento relativo às Orientações Educacionais complementares aos Parâmetros Curriculares Nacionais para o ensino de Física (BRASIL, 2002) destaca, dentre as principais competências em Física a serem desenvolvidas pelos estudantes ao concluírem o processo de escolarização ao final da Educação Básica, a importância de:

Promover e interagir com meios culturais e de difusão científica, através de visitas a museus científicos ou tecnológicos, planetários, exposições etc., para incluir a devida dimensão da Física e da Ciência na apropriação dos espaços de expressão contemporâneos (BRASIL, 2002, p.14).

Nesse aspecto, parece-nos importante o estabelecimento desse vínculo desde os processos de formação inicial de professor, principalmente nas Universidades que mantém Centros de Ciências e atividades de divulgação científica.

Diante dessa questão, nesse trabalho, buscamos acompanhar o trabalho de quatro monitores em um museu de ciências, que também são alunos do curso de Licenciatura em Física de uma Universidade Pública Federal.

Nossa intenção foi a de avaliar o desempenho desses monitores e investigar a existência ou não de um vínculo entre os processos de formação inicial do professor com 
as atividades realizadas no Centro de Ciências. Por isso nossa pesquisa se estabeleceu numa universidade que mantém um Museu de Ciências.

Focamos nossa atenção à correção dos conceitos científicos abordados no processo interativo. Realizamos, também, uma entrevista estruturada a partir de uma única questão: qual a principal dificuldade enfrentada para planejar e conduzir sua apresentação no Centro de Ciências?

Nesse sentido, nossa pesquisa tem por objetivo identificar alguns aspectos que poderiam ser levados em conta na estruturação das atividades de monitoria para a atuação em Museus e Centros de Ciências.

\section{A pesquisa}

Originalmente, participaram de nossa pesquisa seis monitores, todos eles alunos do curso de Licenciatura em Física de uma Universidade Federal. Contudo, neste trabalho, analisamos a participação de apenas quatro deles. Nossa escolha deveu-se às condições de gravação do diálogo estabelecido entre o monitor e os visitantes.

Além disso, realizamos uma entrevista com cada um dos monitores, buscando conhecer qual a principal dificuldade enfrentada por eles na direção da atividade com os visitantes.

Caracterizaremos os monitores como mostrado na tabela a seguir (Tabela 1)

A ação dos licenciandos, em seu trabalho de mo- nitoria, foi acompanhada durante as visitas de quatro escolas públicas estaduais das séries iniciais do Ensino Fundamental, sendo uma visita de uma classe da segunda série, duas da terceira série e uma da quarta série.

Antes de iniciarmos a coleta de dados, marcamos uma reunião de planejamento com os monitores. Nela buscamos definir que demonstração experimental seria vídeo gravada.

A demonstração escolhida para ser apresentada aos visitantes foi a do Gerador eletrostático de Van De Graaf. Nela, um aluno-visitante é convidado a subir em uma pequena plataforma de madeira e tocar com a mão a cúpula do gerador - observa-se, então, que os cabelos do visitante tendem a se repelir.

Optamos por essa demonstração pela livre escolha dos próprios monitores. Durante a reunião de planejamento da atividade, eles afirmaram que se sentiam mais a vontade com esse equipamento, tendo em vista o grande interesse manifestado pelos visitantes.

Os monitores eram alunos do Curso de Licenciatura em Física e a maioria já havia cursado disciplinas tanto de conteúdos específicos quanto de pedagógicos. Além disso, haviam sido selecionados para atuarem no Centro de Ciências mediante uma prova.

Em nossa investigação buscamos avaliar quais fatores da fala do monitor eram importantes para o enriquecimento do processo interativo, com vistas à aprendizagem, entre os ouvintes participantes das atividades no Museu de Ciências. Dessa forma, focamos nossa atenção em dois principais aspectos da interação desencadeada

Tabela 1. Caracterização dos monitores

\begin{tabular}{|c|c|c|}
\hline Monitores & Idade & $\begin{array}{c}\text { Ingresso na } \\
\text { Universidade }\end{array}$ \\
\hline M1 & 19 & 2011 \\
\hline M2 & 20 & 2009 \\
\hline M3 & 23 & 2007 \\
\hline M4 & 22 & 2008 \\
\hline
\end{tabular}


entre monitores e visitantes:

- O domínio conceitual do conteúdo científico abordado nas explicações que construíam para discutir as demonstrações;

- Os mecanismos utilizados para promover reflexões sobre questões sócio científicas.

As interações dialógicas foram gravadas e, em seguida, transcritas para que pudessem ser analisadas.

Com relação ao domínio conceitual da fala dos monitores, utilizada para explicar, aos visitantes, o funcionamento e o efeito provocado pelo gerador eletrostático, buscamos observar se os conceitos científicos são apresentados de forma correta. A intenção não é analisar se a explicação abarca com profundidade todos os aspectos teóricos que estão envolvidos no funcionamento e no efeito provocado pelo gerador, mas, sim, verificar se a interação promove, de alguma forma, um avanço na compreensão dos visitantes sobre a questão científica abordada.

Do ponto de vista dos mecanismos utilizados para sensibilizar o público quanto às questões sócio científicas, buscamos verificar se a fala dos monitores tem a preocupação de promover, nos visitantes, uma reflexão sobre aplicações do conhecimento científico, discutido na abordagem sobre o dia-a-dia da sociedade, e os impactos positivos e negativos disso na vida das pessoas.

\subsection{Fundamentos da Teoria de Vigotski}

A teoria sócio-histórica apresentada e discutida por Vigotski e seus colaboradores, no início do século XX, é reconhecida por vários autores (e.g. GASPAR, 1993; HOWE, 1996; PINO, 2000) como fundamentada na precedência da cultura sobre o desenvolvimento cognitivo de uma pessoa. A ação cultural, entretanto, por si só, não explica o mecanismo de desenvolvimento que resulta na formação de conceitos. Os aspectos culturais fundem-se com o elemento "histórico", pois o homem usa para dominar o ambiente e seu próprio comportamento, elementos inventados e aperfeiçoados ao longo da sua história social, como a linguagem, ou mesmo a escrita e a matemática.

Vigotski (2001a) apresenta um conjunto de estudos experimentais realizados com o intuito de estudar o processo de formação de conceitos. Afirma que o desenvolvimento do processo cognitivo de pensamento por conceitos começa na infância, "mas as funções intelectuais que, numa combinação específica, constituem a base psicológica do processo de formação de conceitos amadurecem, configuram-se e se desenvolvem somente na puberdade" (VIGOTSKI, 2001a, p. 167). Na evolução do intelecto há vários estágios em desenvolvimento e que muitas vezes coexistem.

Para realizar a descrição das fases e estágios do desenvolvimento cognitivo de uma criança até a adolescência, coordenou um estudo conhecido por Método de Sakharov ou Método da dupla estimulação. Trata-se de uma metodologia em que o sujeito experimental (crianças de diferentes idades, adolescentes e adultos) deveria descobrir o significado de palavras sem sentido, escritas sob a base de objetos de formas e cores diferentes (figura 1).

Esse método, apresentado em diferentes trabalhos do autor (e.g. VIGOTSKI, 2001a e 2001b), consiste, basicamente, em verificar quais processos cognitivos o sujeito utiliza para selecionar os objetos que correspondem ao

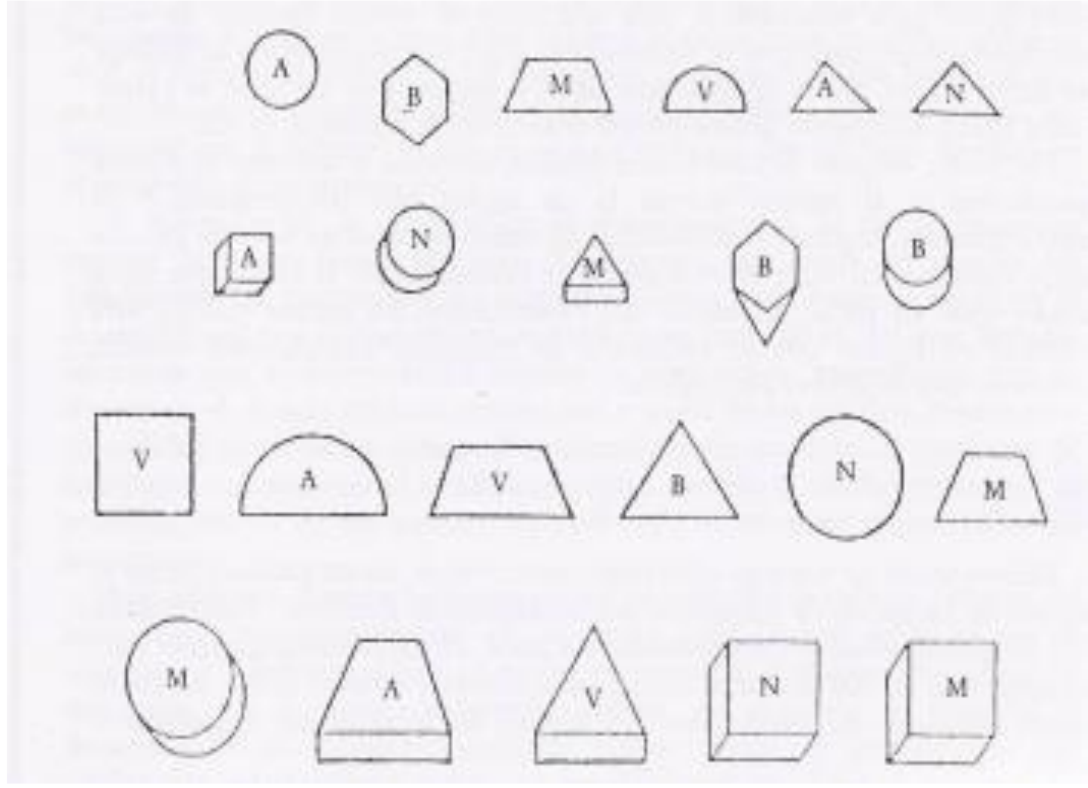

Figura 1. Estudo da formação de conceitos. Método de Sakharov.

Fonte. VIGOTSKI, 2001b, p. 129 
significado de cada palavra, (LAK, BIK, MUR, CEV) inicialmente desconhecidas para o sujeito, mas que tinham um significado associado ao formato de cada um dos blocos apresentados. Para Vigotski, descobrir o significado é descobrir o conceito expresso por aquela palavra. A partir de uma pesquisa realizada com esse material, onde mais de trezentas pessoas foram estudadas, Vigotski estabeleceu fases e estágios de desenvolvimento cognitivo das crianças até a adolescência.

As pesquisas com esse método mostraram que o significado de uma palavra se forma na mente da criança de diferentes maneiras nas etapas sucessivas do seu desenvolvimento. Monteiro (2006) resume esse trabalho de Vigotski, destacando as seguintes etapas:

- As crianças muito pequenas escolhem os objetos relacionados a cada palavra aleatoriamente. Essa etapa é chamada de agregação desorganizada.

- Em uma etapa posterior, a criança cria o significado das palavras pelos mais diferentes elos ou relações, como associações (cor, forma, tamanho) ou encadeamentos (quadrado verde, verde alto, alto e largo, largo e azul). Esse estágio de pensamento é chamado de pensamento por complexos.

- Na etapa seguinte a criança parece capaz de descobrir a palavra que denomina um dos grupos de objetos, mas os experimentos mostram que não têm a coerência lógica que um conceito verdadeiro exige. A criança ainda pensa por complexos, embora com estrutura aparentemente igual à da formação de um conceito. Por essa razão, esse é chamado estágio dos pseudoconceitos.

- Somente a partir da adolescência as pessoas se tornam capazes de entender e definir o significado das palavras. Esse estágio final é o estágio dos conceitos, que marca a formação do verdadeiro pensamento linguístico.

Como destaca HOWE (1996), o termo "Conceito Científico", utilizado por Vigotski, está especialmente associado a conhecimentos sistemáticos e o termo "Conceito Espontâneo", a conceitos não-sistemáticos, adquiridos na experiência cotidiana. Vigotski classificou como científico o aprendido na educação formal e como espontâneo o originário de uma aprendizagem informal, ainda que seja possível destacar a interligação e a influência entre ambos.

Estudos empíricos levaram Vigotski (2001a) a concluir que a criança utiliza conceitos espontâneos antes de compreendê-los conscientemente, ou seja, antes de ser capaz de defini-los de forma mais sistemática.

Vigotski (2001a) apresenta, para exemplificar essa ideia, a formulação da Lei de Arquimedes e do conceito de irmão por parte de uma criança. Para o autor a criança tem mais facilidade em sistematizar sobre a Lei de Arquimedes, apresentada formalmente pelo professor, do que em relação ao conceito de irmão, pois a criança não recebeu essa definição formal, mas apenas informalmente, do seu cotidiano, conforme já havia sido destacado por Piaget. Ele oferece também outros exemplos, como a influência positiva da aprendizagem formal de uma língua estrangeira em relação à aprendizagem da nativa, pois a aprendizagem da estrangeira conscientiza e destaca, para o aprendiz, características peculiares de sua língua nativa e ambos os conceitos se enriquecem.

Em linhas gerais, podemos afirmar que para Vigotski, quando um determinado conceito científico é apresentado de forma sistematizada na escola, a sua aprendizagem apenas se inicia. O ensino formal promove o começo da aquisição de um conceito científico. A aplicação desse conceito sistematizado em situações do cotidiano, bem como a vivência de uma experiência concreta junto a uma estrutura científica, são tarefas importantes, que colaboram entre si, em aperfeiçoamento, até que o conceito se torne verdadeiro.

Para Monteiro (2006), apesar de Vigotski valorizar amplamente a interação social como fator essencial para a elaboração de conceitos verdadeiros e, consequentemente, para o desenvolvimento cognitivo, ele não discute quais seriam as condições necessárias que poderiam promover essa interação instrutiva, facilitadora do processo de ensino e aprendizagem.

Wertsch (1984), estudioso da teoria de Vigotski, propôs três construtos teóricos para compreender melhor e tornar mais eficiente um processo interativo com vistas à aprendizagem. Para ele uma interação só atingirá esse objetivo se for compreendido e aceito entre os parceiros. Para tanto, é preciso que haja uma definição de situação, um processo intersubjetivo e uma mediação semiótica.

A definição de situação é a forma como o contexto da interação é visto ou entendido pelos seus participantes.

Isso significa que, quando um adulto e uma criança interagem em um mesmo contexto, por exemplo, a resolução de um problema ou o desenvolvimento de uma tarefa, cada um pode entender a situação de forma diferente e, por isso, cada um tende a resolver o problema ou realizar a tarefa, utilizando uma metodologia, também de forma diferente, ainda que ambas possam se finalizar no mesmo resultado.

Durante a interação, entretanto, um dos participantes pode ter uma compreensão mais específica sobre a definição do outro e, através de uma mudança qualitativa, "redefinir" a situação, sua ou a do parceiro. Em outras palavras, através de uma ação "intersubjetiva" (entre os sujeitos), um dos parceiros altera sua forma de definir a tarefa, alterando o seu funcionamento intrapsicológico. Surge daí mais um construto teórico característico de um processo interativo eficaz para a aprendizagem, a "intersubjetividade".

A intersubjetividade existe somente quando ao menos um dos participantes da interação tem plena consciência da definição de situação feita por si próprio e aquela feita pelo parceiro, a respeito da tarefa proposta. Dessa forma, há níveis diferentes de intersubjetividade: ela pode 
ser básica quando, por exemplo, só há acordo quanto ao local onde se realiza a tarefa, ou pode ser completa quando os participantes têm exatamente o mesmo entendimento da tarefa a ser realizada e dos recursos materiais ou simbólicos que devem ser empregados (MONTEIRO, 2006).

O mecanismo que permite a negociação é o terceiro construto teórico estabelecido por Wertsch (1984), a mediação semiótica. O uso de formas adequadas de mediação semiótica na comunicação entre o adulto e a criança é o que possibilita o estabelecimento da intersubjetividade. A mediação semiótica é toda a simbologia de que adultos e crianças ou professores e alunos dispõem para o estabelecimento da intersubjetividade em uma interação social e, portanto, perpassa pela linguagem oral, gestual, escrita, matemática, apresentações experimentais, analogias, entre quaisquer outros mecanismos culturais que possam facilitar e promover o processo interativo.

\section{Análise dos dados}

Os dados apresentados a seguir são excertos das interações estabelecidas entre os monitores e os visitantes (Quadro 1)

O monitor propõe uma definição de situação pouco adequada a uma demonstração científica. Na proposta apresentada por ele, fica implícito um objetivo pouco significativo para os objetivos da mostra. A predisposição dos alunos para buscar interagir visando uma explicação para o efeito fica circunscrita à observação do efeito que a máquina gera ao ser ligada. Ao invés de se propor explicar e justificar os efeitos da eletricidade estática, a ênfase foi dada no modo inusitado de "bagunçar os cabelos".

Esse tipo de abordagem, apesar de simpática e bastante informal, feita talvez com a intenção de motivar o visitante, posiciona-o na condição de mero expectador. Não o convida a raciocinar e buscar resposta a um problema.

Da forma como foi feita, a definição de situação desvia a atenção do visitante em relação à explicação científica, bem como os conceitos nela envolvidos, fazendo com que o visitante se contente, apenas, com a visualização do efeito.

Apesar de fazer uma pergunta, "Vocês sabem por que isso acontece?", o monitor não estimulou nem esperou a resposta dos alunos. Antes que isso pudesse acontecer ele mesmo respondeu. Nesse sentido, o processo de interação social foi pouco explorado. Do ponto de vista dos construtos de Wertsch (1984), a pouca oportunidade de interação inviabilizou a ocorrência da intersubjetividade, limitando a possibilidade do monitor conhecer a definição de situação dos alunos ou de estimular meios complementares favoráveis à compreensão dos alunos com o equipamento.

Portanto, não há qualquer retorno, por parte dos vi-
Quadro 1 - Excertos da interação promovida pelo monitor 1

\begin{tabular}{|c|}
\hline $\begin{array}{c}\text { Licenciando-monitor: M1 } \\
\text { Público-alvo: Terceira série do Ensino } \\
\text { Fundamental. }\end{array}$ \\
\hline $\begin{array}{c}\text { Demonstração: Arrepiar cabelos com o gerador de } \\
\text { Van De Graaf }\end{array}$ \\
EXCERTOS DA INTERAÇÃO: \\
M1: Quem quer bagunçar os cabelos? \\
A1: Eu não, tenho medo! \\
A2: Eu quero, tio..... \\
M1: E quem quer ver o raio? \\
A3: Eu, Eu,Eu..... \\
M1 fala para A2: Então coloque as mãos aqui e não \\
solta, tá, vai fazer um barulho, não precisa ter \\
medo, não... Não solta a mão, tá! \\
A4: Nossa... Tá subindo! [os cabelos de A2] \\
A5: que legal, A2, seu cabelo tá todo arrepiado. \\
M1: Vocês sabem por que isso acontece? \\
M1: O cabelo dela [A2] fica eletrizado... .com cargas de \\
mesma polaridade que se repelem... aí o cabelo arrepia.
\end{tabular}

$\mathrm{M}_{1}$ : Agora vamos ver quando eu pego essa outra bola e aproximo dessa grandona aqui, ó. O que vocês estão vendo?

A1,A2, A3 todos respondem: Nossa, é um raio.

A4: Nossa, tio, tá fazendo um barulho...

A6: É igual a um relâmpago!

M1: Isso. Por que será que isso acontece?

A7: Ah não sei, não... deve ser da eletricidade que tá aí.

B6: Aí onde?

A7: Aí na bolona grande.

M1: É isso mesmo, quer ver, é mais ou menos assim... a bola grande tá carregada... quando a gente chega com o bastão que tem a bolinha perto essa corrente flui e você vêessa faísca. 
sitantes, de que os termos ou expressões utilizadas pelo monitor, como: eletrização, cargas de mesma polaridade, foram devidamente compreendidas.

Analisando a explicação, em termos de uma superestrutura da linguagem utilizada pelo monitor, pode-se elaborar a seguinte construção argumentativa: o gerador eletriza o cabelo com cargas de polaridade contrárias, que ocasiona a repulsão, cujo efeito é o cabelo arrepiado.

Em decorrência dessa linha de raciocínio, podemos destacar que:

- A afirmação "O cabelo dela fica eletrizado" pressupõe que os alunos visitantes já soubessem o que significa estar eletrizado, o que não é óbvio;

- A expressão "cargas de mesma polaridade" é inadequada; polaridade é um termo utilizado para ímãs, e não para cargas elétricas;

- A relação entre a repulsão elétrica e o arrepiar do cabelo não é óbvia nem direta, por isso não pode ser caracterizada com uma explicação conceitual.

Na última frase do monitor, utilizada para explicar a descarga elétrica, ele procura valer-se de um conceito que o ensino busca superar, a de corrente elétrica como fluido: “(...) a bola grande tá carregada, quando a gente chega com o bastão que tem a bolinha perto essa corrente flui e você vê essa faísca".

Como sabemos, o conceito de corrente elétrica como fluido é uma ideia que remete à Física do século XIX.

A partir do quadro 2, a seguir, podemos observar alguns excertos da intervenção do monitor 2 junto aos alunos visitantes.

A definição de situação proposta inicialmente pelo monitor foi limitada do ponto de vista conceitual. Desejando tornar-se mais simpático às crianças, o monitor propõe que a interação seja desencadeada em torno de uma brincadeira. Apesar de sabermos da importância da ludicidade para a aprendizagem, ao utilizar o termo "brincar", o monitor remete à ideia de uma atividade que não leva, ou não precisa levar, à aquisição de conhecimento. O objetivo da atividade desloca a atenção do visitante para a diversão tão somente. Nesse caso, ele espera o efeito que o divertirá e não se mobiliza para buscar explicações, ideias ou conceitos que justifiquem o fenômeno observado.

A própria natureza do ato de experimentar e de se surpreender com o efeito observado já se constitui em uma vivência lúdica e motivadora. O monitor deve propor ações que levem o visitante além da mera motivação. Deve aproveitá-la visando chamar a atenção para a Física, os conceitos e a explicação do fenômeno. Ao propor a brincadeira como definição de situação inicial ao visitante, o monitor não o encoraja a debruçar-se sobre um problema a ser superado, uma pergunta a ser respondida. Nesse sentido, após brincar com o equipa-
Quadro 2 - Excertos da interação promovida pelo monitor 2

\begin{tabular}{|c|}
\hline Licenciando-monitor: $\mathrm{M}_{2}$ \\
\hline Público-alvo: Quarta série do Ensino Fundamental \\
\hline $\begin{array}{l}\text { Demonstração: Arrepiar cabelos com gerador de } \\
\text { Van De Graaf }\end{array}$ \\
\hline EXCERTOS DA INTERAÇÃO: \\
\hline $\begin{array}{l}\text { M2: Bom dia, gente! Vamos brincar com a eletricidade } \\
\text { um pouco? }\end{array}$ \\
\hline Todos os alunos respondem que querem brincar; \\
\hline $\begin{array}{l}\text { B3: Alguém tem ideia do que é isso? Ou o que isso faz? } \\
\text { (mostra o gerador eletrostático) }\end{array}$ \\
\hline A1: eu não. \\
\hline $\mathrm{A}_{2}$ : nem imagino. \\
\hline M2: então eu vou ligar pra vocês verem; \\
\hline Аз: nossa, faz um barulhão! \\
\hline A4: não estou vendo nada de mais; \\
\hline $\begin{array}{l}\text { M2: Calma, e se agora eu aproximar esse bastão } \\
\text { dessa bola? Alguém imagina o que acontece? } \\
\text { (pausa) }\end{array}$ \\
\hline M2: Nossa, que silêncio! \\
\hline As: Olha, sai uma faísca! \\
\hline A6: Olha... Igual raio; \\
\hline A7: Faz até barulho de raio; \\
\hline $\begin{array}{l}\text { M2: Agora eu preciso de uma menina corajosa pra } \\
\text { colocar as mãos nessa bola. }\end{array}$ \\
\hline As: Claro que ninguém vai, né tio... \\
\hline $\mathrm{M}_{2}$ : Por quê? \\
\hline As: Porque dá choque, né. \\
\hline $\begin{array}{l}\text { B3: Dá choque nada, você acha que eu iria } \\
\text { machucar vocês? }\end{array}$ \\
\hline A9: Não sei; \\
\hline A10: Eu vou, tio. \\
\hline $\begin{array}{l}\text { M2: Temos uma corajosa. Coloca as duas mãos aqui } \\
\text { e não solta... Eu vou ligar o gerador. Você já viu } \\
\text { que ele faz um barulho mas não vai te machucar, } \\
\text { não, tá?.... Não tira a mãozinha, não... Se você tiver } \\
\text { medo me fala que eu desligo, tá? }\end{array}$ \\
\hline A10: Tá, tio, pode ligar. \\
\hline M2: Liguei, tá! \\
\hline A11: Não tá acontecendo nada; \\
\hline A6: Calma... Deve acontecer alguma coisa; \\
\hline A5: Olha o cabelo dela, [A10], tá mexendo. \\
\hline A1: Tá arrepiando! \\
\hline $\mathrm{A}_{2}$ ( (risos) tá tudo em pé $\mathrm{A}_{10}$. \\
\hline Professora: $A_{10}$ seu cabelo tá lindo... Tá todo \\
\hline
\end{tabular}


mento e observar o efeito que ele provoca, não há mais o interesse e, nesse caso, a interação, do ponto de vista da aprendizagem, fica empobrecida, sem almejar um acréscimo aos processos intersubjetivos que poderiam desencadear uma redefinição da situação.

O monitor faz uma sondagem de conhecimento prévio em relação ao equipamento. Essa questão, a nosso ver, é desnecessária, pois seria improvável que um aluno desse nível de ensino conhecesse esse tipo de gerador. Talvez, alguns deles pudessem conhecer seus efeitos, que, como vimos, não contribuiria para a discussão de conceitos científicos, apenas reforçaria a ideia de chamar a atenção para o efeito. A questão pertinente, do nosso ponto de vista, seria perguntar o que os visitantes sabiam sobre eletricidade.

Apesar da pergunta poder ser entendida como uma sondagem de pré-concepções, ela não tem efeito sobre os visitantes e, portanto, não atinge seu objetivo. $\mathrm{O}$ silêncio da maioria e a negativa de um aluno parecem não perturbar o monitor, o quê talvez indique sua pouca habilidade em provocar ações intersubjetivas capazes de redefinir situações.

O monitor lembra aos alunos que é por causa da eletricidade que o fenômeno acontece. Parece claro para o monitor que isso é tudo que os visitantes precisam saber para entender o efeito observado.

É interessante notar que não há nenhuma pergunta sobre a diferença de efeitos que a eletricidade provoca, além dos cabelos que se arrepiam ou a faísca, por exemplo, aceder uma lâmpada. Ou, porque não há choque elétrico ao tocar a esfera do gerador quando se está sobre o banco de madeira?

Essas perguntas, provavelmente, surgiriam se uma interação mais profícua se estabelecesse, em função de uma definição de situação que colocasse os visitantes como investigadores e não só como meros observadores do efeito.

Para explicar o fenômeno observado, o monitor recorre à seguinte estrutura explicativa: "diferença de tensão" encadeia-se com "corrente que flui", depois aparece a "faísca" e, por fim, o elo final da cadeia: "arrepiando os cabelos". A rigor esse tipo de encadeamento de ideias pode parecer adequado a esse nível de ensino. Contudo, além de não ser discutido com os visitantes o que eles entenderam por "diferença de potencial", mais uma vez o uso inadequado do termo "fluir", contribuem para a ineficácia da interação em termos de educação científica.

É interessante que o monitor dá-se por satisfeito quando ouve um visitante afirmar que havia entendido. E preciso destacar que não houve preocupação com o que foi, de fato, entendido.

A seguir, no quadro 3, apresentamos excertos da interação promovida pelo monitor 4 .

Nessa interação o monitor inicia sua fala tentando ganhar a simpatia dos visitantes. Solicita a todos que prestem a atenção, mas não diz a que. Portanto, não é feito qualquer movimento para entender a definição de
Quadro 3. Excertos da interação promovida pelo monitor 4

\begin{tabular}{|c|}
\hline Licenciando-monitor: $\mathbf{M}_{4}$ \\
\hline Público-alvo: Terceira série do Ensino Fundamental \\
\hline Demonstração Arrepiar os cabelos com o gerador de \\
Van De Graaf \\
\hline
\end{tabular}

\section{EXCERTOS DA INTERAÇÃO:}

M4: Oi, Gente! Nossa... que moçada bonita, hein, professora! Agora eu quero saber quem é bem corajoso?

Todos respondem (levantando a mão) que são corajosos;

M4: Então eu quero um voluntário;

$\mathrm{A}_{1}$ : Eu vou.

M4: Olha, eu vou ligar esse equipamento e quero que você fique com as mãos bem grudadas nessa bola, não solta não, tá?... Não precisa ter medo;

A1: Ai !.... Tá fazendo barulho;

M4: Não precisa ficar com medo.... Prestem a atenção no que vai acontecer.

A2: Nossa, tá subindo!

$\mathrm{M}_{4}$ : O que tá subindo?

A3: O cabelo, veio, da [A1]... Olha que doido!

A5: Caraca, cara!

A6: Nossa, tá arrepiadão!....

M4: Viu....Bacana para caramba, né? Agora vamos ver o que acontece quando a gente aproxima essa outra bola perto dessa.

A7: Nossa, acende!...

As: É tipo raio.

A9: Que lindo!

M4: Agora eu quero saber quem sabe me explicar esse fenômeno?

A10: É eletricidade.

M4: Nossa, cara... Você é muito esperto... Quem te ensinou?

A10: Eu que sei, tia.

$\mathrm{M}_{4}$ : Ó, presta atenção... Tá acumulando várias carguinhas aqui nessa bola... Só que essas cargas são tão pequenas que a gente nem consegue ver... Quando a gente põe a mão ou passa a outra bolinha perto [pausa]... a carga pula e acontece uma diferença de potencial e vocês enxergam isso tudo que vocês viram. 
situação do aprendiz ou canalizá-la para um ponto mais próximo da definição do monitor.

Parece óbvio para o monitor que todos sabem a que devem dirigir sua atenção. Nesse caso, isso pode ser verdade, pois os alunos provavelmente já estavam esperando a experiência de arrepiar cabelos. Mas a ideia de que o resultado de uma experiência é evidente, por si só, é falsa. Nem sempre os alunos veem o que devem ver pela simples razão de não saberem o que observar.

$\mathrm{O}$ visitante surpreende o monitor. Ele já sabe a resposta: é a eletricidade!

O monitor, portanto, busca completar a fala do visitante afirmando que "Tá acumulando várias carguinhas aqui nessa bola... Só que essas cargas são tão pequenas que a gente nem consegue ver... Quando a gente põe a mão ou passa a outra bolinha perto [pausa]... a carga pula e acontece uma diferença de potencial e vocês enxergam isso tudo que vocês viram."

Tentando se aproximar da criança, o monitor usa a palavra no diminutivo "carguinhas". É como se ele acreditasse que usando o diminutivo o visitante com-

Quadro 4 - Excertos da interação promovida pelo monitor 3

\begin{tabular}{|c|}
\hline Licenciando-monitor: $\mathbf{M}_{3}$ \\
\hline Público-alvo: Quarta série do Ensino Fundamental \\
\hline Demonstração: Arrepiar os cabelos com o gerador de \\
Van de Graaf \\
\hline
\end{tabular}

EXCERTOS DA INTERAÇÃO:

M3: Essa máquina aqui é o gerador de Van de Graaf. Van de Graaf foi a pessoa que inventou. E gerador...

O que vocês entendem por gerador? Gerador de que?

A2: Eletricidade

M3: Eletricidade, muito bem. Mas, como assim? Quanto de eletricidade? Será que isso daqui gera muito ou gera pouca eletricidade?

A1: Muita.

M3: E como eu sei que é muita eletricidade? Como eu sei que é muita ou é pouca eletricidade?

A2: Volts.

M3: Quantos volts você acha que é muita eletricidade?

$\mathrm{M}_{3}$ : Como fazer para o cabelo dela abaixar?

A: Eu sei, eu sei! (...)

A7: [Interrompendo] Desliga

B4: Sem desligar

As: Tira a mão

M3: Sem tirar a mão dela

A9: Encosta o pedaço de ferro (Referindo-se ao fio terra) preenderia melhor seu significado. O que, obviamente, não se justifica.

O monitor ainda afirma, erroneamente, que as cargas elétricas pulam, sem justificar o porquê. Além disso, destaca que, por causa das cargas pularem, ocorre uma diferença de potencial.

O monitor M3 também não faz investigações sobre a definição de situação dos alunos. Ele inicia sua interação com os visitantes apresentando o equipamento de demonstração, mas interrompe sua fala para consultar os alunos sobre o significado de gerador.

Ao ouvir a palavra "eletricidade", o monitor se satisfaz, porém propõe outra questão aos visitantes: Quanto de eletricidade? Será que isso daqui gera muito ou gera pouca eletricidade? E como eu sei que é muita eletricidade? Como eu sei que é muita ou é pouca eletricidade?

Surpreendentemente, ele ouve dos visitantes o termo "volts". Mais surpreendentemente ainda é o fato dele não explorar essa resposta e fazer outra pergunta: "Quantos volts você acha que é muita eletricidade?".

Como não há respostas por parte dos visitantes, o monitor muda de assunto e pergunta: "Como fazer para o cabelo dela abaixar?" Assim, subentende-se que o monitor justifica o motivo dos cabelos se arrepiarem devido ao aparelho gerar eletricidade em grande quantidade, apesar de não fazer nenhuma menção explícita disso.

Com a nova pergunta, o monitor parece crer que os visitantes sejam capazes de, a partir da observação do fenômeno, relacionar o fato do cabelo abaixar com a ação que ocorre quando o fio-terra é encostado no equipamento.

Depois de algumas tentativas, um visitante dá a resposta que o monitor deseja ouvir. A partir disso, a interação é encerrada, sem uma explicação dos fenômenos observados.

Provavelmente, aqueles visitantes já haviam assistido aquela demonstração e, portanto, foram capazes de apresentar respostas prontas do monitor.

Em geral, podemos concluir que:

- As explicações mostram sérias deficiências conceituais dos monitores;

- Apesar de todas as explicações seguirem a estrutura cognitiva de complexos em cadeia, o que, segundo Vigotski, é adequado ao nível cognitivo dos alunosvisitantes, o que nos pareceu é que elas não foram consequência da preocupação do monitor. Porém, evidenciaram o nível de compreensão do monitor sobre a tarefa a ser realizada. A nosso ver, o monitor, de forma "inconsciente", deixou claro sua própria definição de situação sobre a tarefa que deveria ser realizada, associada com a ideia de que a atividade experimental serviria, única e exclusivamente, para a motivação das crianças participantes, como incentivo ao lúdico e ao agradável, sem possibilidades de maiores alcances conceituais. 
- Na maioria dos casos, o monitor não se preocupou em estabelecer, ou restabelecer, uma definição de situação entre todos os participantes da interação;

- Ficou claro que, para a maioria dos monitores, entender é acertar a resposta e não compreender o fenômeno apresentado;

- A preocupação com o entendimento dos alunos foi sempre burocrática: se os visitantes dizem que entenderam é porque entenderam;

- A linguagem ou mediação semiótica empregada foi acessível aos alunos-visitantes muito em função do próprio equipamento de demonstração utilizado, por exemplo, quando ao ver a descarga elétrica do efeito corona, os alunos associam o fenômeno ao termo raio. No entanto, a falta de aprofundamento conceitual das discussões por parte do monitor limitou a ocorrência de intersubjetividade, ou seja, a negociação de significados com eles foi praticamente irrelevante.

Na entrevista realizada com os monitores, cuja questão principal era avaliar as principais dificuldades enfrentadas por eles no trabalho de prepararem e realizarem a apresentação das demonstrações aos visitantes, observamos que eles destacaram algumas deficiências no curso de formação que, do nosso ponto de vista, costuma ser comum na maioria dos cursos de formação inicial de professores.

Quanto às deficiências apresentadas pelos licenciandos-monitores, vamos nos limitar a apresentar suas próprias queixas e justificativas. Para eles, os professores das disciplinas oferecidas no curso de licenciatura não estabelecem relações entre os conteúdos específicos de Física aos conteúdos pedagógicos, como destacamos nos excertos a seguir:

M1: Os nossos professores dão a disciplina como se nós fossemos alunos do bacharelado é só conta, conta, conta e cálculo... Eu acho que deveria dar uma aplicação... Sei lá, algo mais didático. Tem muita teoria, coisa que a gente nunca vai falar numa sala de aula... Eu acho que tinham que nos ensinar como explicar, sei lá... Força de Newton, por exemplo, numa escola totalmente sem recurso.

M2: Nossas aulas são bem focadas em conteúdos específicos mesmo, sem nem tocar nas disciplinas de educação. Nunca fizeram uma ligação entre conteúdo e didática.

M3: Em todas as nossas disciplinas não há uma preocupação com a transposição didática dos conteúdos em sala de aula [...]. Só se tem a preocupação de ensinar a teoria, as contas. Em nenhum momento da aula eles param e falam "Ó, quando vocês forem dar aula, façam desse jeito" é, assim, eles não se preocupam como a gente vai aplicar isso em sala de aula.

M4: Olha... Museus, centros de ciências ou feira de ciências nunca foram falados para gente em sala de aula, parece que a física é até diferente. Nunca surgiu do professor essa ideia, de que espaço de educação não é só a escola, pode ser outros lugares, isso até agora não apareceu.

Outra crítica apresentada pelos licenciandos destaca a pouca importância dada à licenciatura, pelos professores do curso de Física, que só dão valor para o curso de bacharelado, como mostram os trechos abaixo:

M2: Os professores sempre zoam da gente, falando que licenciatura é para meninas... Que homem faz é bacharelado...

M1: Quando a gente pede uma aplicação prática de algum tópico, eles [professores] dizem que isso é pra licenciatura, que na aula é o cálculo, a demonstração da fórmula que é importante... E se a gente questiona, falando que quer fazer licenciatura, ele desconversa e acaba não dando uma aplicabilidade plausível para gente falar em sala de aula, como exemplo para nossos alunos...

Percebe-se, ainda, claramente pela fala dos licenciandos, que, durante as disciplinas específicas de Física, a aplicabilidade dos conceitos à vida cotidiana não é abordada pelos professores, o que certamente vai dificultar o trabalho deles quando precisarem ou pretenderem apresentá-las a seus alunos. Pode-se, ainda, lembrando a relação cognitiva mutuamente reforçadora entre conceitos científicos e espontâneos da teoria de Vigotski, supor que a falta dessa ligação tenha sido uma barreira para que os licenciandos tivessem aprendido adequadamente o conteúdo. Nesse sentido, destacamos a crítica de um deles aos professores da licenciatura, que ministram as disciplinas pedagógicas, por não incentivarem a utilização de espaços informais de educação:

M3: Olha, eu, até agora, na minha aula, nunca ouvi um professor falar em visitar um centro de ciências e nem a incentivar que se façam feiras de ciências na escola para estimular a busca pelo conhecimento e a curiosidade dos alunos.

M4: Eu acho que a gente deveria questionar mais com nossos professores sobre a utilização desses espaços, pois eles são importantes... um não exclui o outro, pelo contrário, eu acho que eles se complementam.

M2: Os alunos, se fossem incentivados a visitarem os centros de ciências ou a participarem de feira de ciências... Eles poderiam perceber como é fácil montar algumas experiências e como que se aprende quando a gente busca esse conhecimento.

\section{Considerações finais}

O primeiro aspecto a considerar foi a constatação da validade do uso de instituições de ensino não formal, como os museus e centros de ciências, para avaliar a qualidade da formação de licenciandos em física. Ficou claro para nós que o desafio apresentado aos licenciandos, de apresentar demonstrações experimentais a alunos do 
ensino fundamental, tornou evidentes suas deficiências conceituais que comentaremos mais adiante. Tendo em vista que essas apresentações tiveram a duração de apenas alguns minutos, parece-nos clara a potencialidade, conveniência e praticidade que elas evidenciaram como instrumentos de avaliação da formação dos licenciandos investigados. Pode-se antever as amplas possibilidades que essa prática pode oferecer para os estágios de formação docente, não só para o licenciando, que apresenta a demonstração, mas para todos os demais, pelas enriquecedoras discussões que elas podem propiciar, desde que bem orientadas pelo professor, o que ficou claro nas análises aqui apresentadas.

Apesar de essa pesquisa limitar-se à análise das apresentações das demonstrações, no sentido de diagnosticar deficiências de formação, parece-nos clara, também, a possibilidade de empregá-las para a melhoria dessa formação, tanto pela ênfase em estratégias didáticas voltadas à experimentação, que nem sempre são satisfatoriamente contempladas nos cursos de licenciatura, como pelo domínio conceitual exigido, em que o professor não conta com o apoio da lousa e, principalmente, do suporte das formulações matemáticas com as quais, costumeiramente, se socorre para apoiar suas explicações.

A apresentação de demonstrações experimentais exige do professor um discurso que deve aliar à motivação uma abordagem, ao mesmo tempo conceitualmente correta e adequada ao nível cognitivo do aluno. Essa tarefa está longe de ser trivial.

Concordamos com a visão dos licenciandos que apontam para a importância das atividades realizadas nos espaços não formais de educação, para a formação do professor de disciplinas científicas, tendo em vista as exigências conceituais e didáticas que essa atividade impõe.

Como nossa pesquisa deixou claro, apresentar uma demonstração científica exige, em primeiro lugar, o domínio dos conteúdos científicos dessa demonstração e, em segundo lugar, é o conhecimento de fundamentação pedagógica adequada que oriente essa apresentação. Por isso, um dos nossos objetivos futuros, resultantes deste trabalho, é planejar e apresentar um curso de formação que possa ser ministrado em museus e centros de ciências.

Acreditamos, ainda, que os estágios supervisionados, aspecto nuclear da formação de professores em qualquer projeto político-pedagógico, devam contemplar a monitoria em Centro de Ciências, que pode oferecer a oportunidade única de os licenciandos interagirem com os alunos e professores em um ambiente informal, livre das limitações de horário, conteúdo e abordagem, característicos do ensino formal restrito à sala de aula.

Assim, o projeto pedagógico, de um curso efetivamente interessado na articulação teoria e prática, deve ter como aspecto primordial a valorização das atividades práticas realizadas em espaços não formais. Nesse sentido, os estágios supervisionados nesses ambientes precisam ser incluídos no desenho curricular dos cursos de licenciatura.

Acreditamos que a inserção das atividades em centros de ciências deve respeitar a trajetória de trabalho e as condições institucionais de cada curso e seus docentes, razão pela qual não gostaríamos que nossa proposta tivesse caráter homogeneizador ou normativo. Estamos cientes de que a sugestão aqui registrada leva tempo para ser efetivada e pressupõe, necessariamente, alterações das condições institucionais a que estamos submetidos.

Propor um processo que implique em novos rumos para a prática educativa é ter a coragem de inovar e de colocá-la em consonância com as diretrizes de formação de professores, apresentando-a como uma alternativa viável de melhoria da qualidade do ensino. Acreditamos que a validade do uso do ambiente do centro de ciências, para atividade de complementação da formação inicial e continuada dos professores, é essencial para a melhoria da formação conceitual e pedagógica dos professores de física.

\section{Referências}

BRASIL, Instituto Nacional de Pesquisas Educacionais - INEP. Resultados preliminares PISA, 2012a.

Disponível em http://www.inep.gov.br/downloads/ internacional/pisa/2010/pisa2009/. Acesso em 10 de mar. de 2013.

BRASIL, Anuário Brasileiro da Educação Básica 2012b. 160p. Disponível em: http://pnld.moderna. com.br/2012/06/07/baixe-ja-anuario-brasileiro-daeducacao-basica-2012/. Acesso em 20/04/2013.

BRASIL, Secretaria de Educação Média e Tecnológica. PCN+ Ensino Médio: orientações educacionais complementares aos Parâmetros Curriculares Nacionais. Ciências da Natureza, Matemática e suas Tecnologias. Brasília: MEC, SEMTEC, 2002.

GRUZMAN, C.; SIQUEIRA, V. H. F. O papel educacional do Museu de Ciências: desafios e transformações conceituais. Revista Electrónica de Enseñanza de las Ciencias Vol. 6, № 2, 402-423 (2007).

HOWE, A. C. Development of science concepts within a vygotskian framework. Science Education 80(1), pp. 35-51, 1996.

LURIA, A. R. Diferenças culturais de pensamento. In: VIGOTSKI, et al. Linguagem, desenvolvimento e aprendizagem. p. 39 - 58. São Paulo: Ícone editora, 2001.

MARANDINO, M.. Interfaces na relação museuescola. Cad.Cat.Ens.Fís., v. 18, n.1: p.85-100, abr. 
2001.

MARANDINO, M. A formação inicial de professores e os museus de Ciências. In: SELLES, Sandra E. e FERREIRA, Márcia S. (Orgs.). Formação docente em Ciências: memórias e práticas. (p. 59-76). Rio de Janeiro: EdUFF, 2003.

MONTEIRO, I. C. de. C. Estudo dos processos interativos em aulas de física: uma abordagem segundo a teoria de Vigotski. 2006. 204f. Tese (Doutorado em Educação para a Ciência, Área de Concentração: Ensino de Ciências). Faculdade de Ciências, UNESP, Bauru, 2006.

PEDRETTI, E.G. Learning about Science Through Science Centre Exhibitions. Paper presented at the International Science Museum and Science Teaching and Learning Conference. Taiwan, Kaohsiung: National Kaohsiung Normal University, 2006.

VALENTE, M. E., CAZELLI, S. e ALVES, F.: Museus, ciência e educação: novos desafios. História, Ciências, Saúde - Manguinhos, vol. 12 (suplemento), p. 183-203, 2005.

VYGOTSKY, L. S. A formação social da mente. 7 ed. São Paulo: Martins Fontes, 2007.

VIGOTSKI, L. S. A construção do pensamento e da linguagem. São Paulo. Editora Martins Fontes, 2001a.

VIGOTSKI, L. S. Obras escogidas: problemas de psicologia general. Tomo II. Madrid: A. Machado Libros, primeira edição 1993, 2001 b.

WERTSCH, J. V. - The Zone of Proximal Development: Some Conceptual Issues, In: Rogoff, B. e Wertsch, J. V. (ed.): Childrens Learning in the Zone of Proximal Development - New Directions to Child Development, nํㅡㄹ 23 - S. Francisco; Jossey Bass, Março, 1984. 